few warts with the drug often results in a spontaneous regression of all. We instruct all patients to wash off the paint four to six hours after its application and thereafter to apply hydrocortisone lotion $1 \%$ twice a day for several days. These two measures prevent local reactions without interfering with antimitotic activity.

When extensive wart growths are found after the thirtieth week of pregnancy we do no more than treat any coexisting condition -for example, trichomoniasis, candidiasis, or gonorrhoea. Experience shows that even extensive warts disappear spontaneously after delivery. This happened even in two cases in which intragenital and extragenital warts were so widespread that caesarian section was seriously considered.-We are, etc.,

R. S. MORTON M. N. BHATtACHARYYA

Department of Venereology,

Royal Infirmary,

SIR,-The report on the toxic effect of podophyllum application in pregnancy (12 August, p. 391) is of considerable interest and importance. Though fortunately this serious neuropathic toxic effect must be a rare complication, it deserves to be widely known. However, I would question the authors' conclusion that podophyllum resin should not be used on anogenital warts.

Podophyllum had been used for several years for anogenital warts before the article by I. W. Kaplan ${ }^{1}$ which brought it to general notice. The skin toxic and cytotoxic (colchicine-like) effects of podophyllum resin and of podophyllotoxin were investigated by M. Sullivan and L. S. King, 3 who also confirmed its therapeutic efficiency. It would be fair to say that podophyllum resin has been the standard treatment of this type of wart for over 26 years.

Dr. M. J. Chamberlain and colleagues are correct when they say that when the warts are red, congested, florid, and friable then absorption of podophyllum may occur. However, this more severe presentation is usually associated with discharge either from the vagina or from the macerated warts themselves. Preliminary cleansing with antiseptics or astringents over a period of days would diminish the vascularity of the warts and heal the breaches on the opposing clefts and folds of the warty mass. Absorption of medicament would be then less likely to occur. Again the concentration and amount of podophyllum used must be of some relevance to the amount absorbed.

As the local response is variable, I usually commence with $10 \%$ podophyllum resin in Friar's balsam, and a limited area would be treated, using 1-2 $\mathrm{ml}$. The strength of the application could be increased to $20 \%$. (The B.N.F. dispenses a $15 \%$ concentration of podophyllum in Friar's balsam.) Before podophyllum the use of the cautery or diathermy for anogenital warts was the usual procedure. The cautery is preferable to diathermy as it is not always certain how deep an electrical burn may be. A general anaesthetic is needed, with its attendant risk, however small. The use of the cautery or diathermy on large masses of warts, which may obscure the anatomy of the vestibule and of the urethral orifice, is an anxious experience for the operator, for scarring and infection may follow. In short, while I would agree that podophyllum is best avoided during pregnancy, it is still the method of choice for anogenital warts provided the amount and concentration of the resin used is carefully regulated.-I am, etc.,

London N.W.1

LOUIS FORMAN 1 Kaplan, I. W., New Orleans Medical and Surgical
Fournal, 1941, 94, 388.
2 Sullivan, M., and King, L. S., Archives of Der-
matology and Syphilology, 1947, 56, 30.
3 Sullivan, M., Archives of Dermatology and
Syphilology, 1949, 60, 1.

SIR,-Dr. M. J. Chamberlain and others (12 August, p. 391) draw attention to the toxic effect of podophyllum and state it should never be used in pregnancy or in circumstances where warts are so florid, with a large surface area, or haemorrhagic that absorption is likely.

I was consultant venereologist to the Mothers' Hospital for three years and saw about 600 new patients each year, all in various stages of pregnancy. About 5\% of these women had warts which were treated with podophyllum $20 \%$ in spirit, and they usually responded to treatment. The few that did not were removed by hyfrecator. All patients were told to wash off all traces of podophyllum three hours after application to avoid local reaction and absorption. I have never seen any evidence of peripheral neuropathy or intrauterine death which could be associated with podophyllum.-I am, etc.

Royal Northern Hospital,

G. JELINEK

Royal Norther

SIR,-Dr. M. J. Chamberlain and his collaborators have described (12 August, p. 391) the adverse effects which followed the application of podophyllum resin to vulval warts in the later months of pregnancy.

Vulval warts, for reasons which are obscure, are often particularly extensive during pregnancy.1 However, they usually regress during the puerperium and may disappear completely. ${ }^{23}$ In view of this it might be thought advisable to restrict treatment during pregnancy to diathermy excision of the larger wart masses if these appear likely to bleed or obstruct labour, but otherwise to defer treatment until the puerperium. Any warts then remaining will be smaller and much easier to treat.-I am, etc.,

Department of Venereology,

J. D. ORIEL London $\mathrm{W} .6$ 1 Oriel, J. D., British fournal of Venereal Diseases,
1971, 47, i.
2 Gorthey, R. L., and Krembs, M. A., Obstetrics
Gynecology, 1954, 4, 67.
3 Hingorani, V., and Kaur, R., Fourmal of Obstetrics
and Gvnaecology of the British Commonwealth,
1961, 68, 288.

Duodenogastric Reflux and Pyloric Surgery

SIR,-We were interested to read the letter from Mr. J. O. Kilby (22 July, p. 235). Stimulated by the work of Capper and o'hers, ${ }^{12}$ we have studied the phenomenon of duodenogastric reflux during the past three years. While the evidence produced by these workers is convincing, it seemed to us that the method of duodenal intubation for assessing duodenogastric reflux was not physiological. Contrary to what Capper and his coworkers have stated, we believe that it is possible to observe the competence or otherwise of the pylorus during an ordinary barium meal examination and it may be of interest to radiologists and others to describe this technique.

After filling the duodenum, in particular the duodenal cap, with barium (usually in the prone oblique position with the right side down) the patient is turned quickly into the supine oblique position with the right side raised. In this situation the gastric antrum contains the normal gas bubble and during duodenal systole reflux of barium from the duodenum through the pylorus into the gastric antrum, or conversely the $a b$ sence of such reflux, may be easily observed.

The results of our observations in some 300 patients referred for barium meal examination and of 25 normal volunteers will shortly be presented for publication. While it is true to say that these observations are of a preliminary nature and require confirmation, we have been unable to verify the observations of Capper and others that duodenogastric reflux occurs significantly more frequently in patients with gastric ulcer. On the contrary, we have found a similar incidence of duodenogastric reflux in all groups studied, including normal volunteers. Preliminary studies, however, do tend to support Mr. Kilby's observations on the decreased incidence of duodenogastric reflux in patients after pyloroplasty.-We are, etc.,

W. B. JAMES

D. A. R. ROBERTSON G. R. SUTHERLAND

Department of Radiology,

Glasgow

1 Capper, W. M., Annals of the Royal College of Surgeons of England, 1967, 40, 21.
Lancet, 1966, 2, 621. G. R., and Kilby, J. O.,

\section{Treatment of Muscular Dystrophy}

SIR.-Many attempts have been made in the past to discover an effective drug treatment for the muscular dystrophies. Most of the reports concerning the human diseases were based on uncontrolled observations, a notoriously hazardous basis. Thus early descriptions of the beneficial effects of mixtures of nucleosides and nucleotides (Laevadosin) were not substantiated by a prolonged controlled trial.1 Vitamin E, deficiency of which causes a myopathy in experimental animals, has also failed significantly to improve patients with muscular dystrophies. ${ }^{2}$ Uncontrolled favourable reports of the effects of anabolic steroids were not substantiated by controlled trials. ${ }^{3}$ A report of the beneficial effect of a vasodilator agent, butyl sympathol," awaits investigation by a controlled trial.

On the other hand, a number of different factors have been reported significantly to benefit mice of the Bar Harbor $129 \mathrm{Re}$ strain with muscular dystrophy. These include a diet rich in protein and lipid, digitalis derivatives anabolic steroids. aldosterone antagonists, purines and pyrimidines, and propylene glycol, while vitamin $\mathbf{E}$ ubiquinone, adenosine triphosphate, reserpine, cortisone, and a diet deficient in phenylalanine were all without benefit. ${ }^{5}$ 